\title{
Pre-service science teachers' processes of establishing simple electric circuits
}

\begin{tabular}{|c|c|}
\hline Department of $M c$ & $\begin{array}{c}\text { Cezmi Ünal* } \\
\text { d Science Education, Faculty of Education, Tokat Gaziosmanpaşa } \\
\text { University, Tokat, Turkey } \\
\text { ORCID: 0000-0002-6894-2286 }\end{array}$ \\
\hline Article history & The aim of this research is to identify pre-service science teachers' \\
\hline $\begin{array}{l}\text { Received: } \\
20.03 .2021\end{array}$ & $\begin{array}{l}\text { experiences during the simple electrical circuit establishment process, } \\
\text { points they were challenged with, and developed strategies they used }\end{array}$ \\
\hline $\begin{array}{l}\text { Received in revised form: } \\
05.06 .2021\end{array}$ & $\begin{array}{l}\text { against the challenges they were experimenting with this process. In this } \\
\text { study, embedded single case study, which is one of the qualitative } \\
\text { research methods, was used. The case was two weeks of tertiary level }\end{array}$ \\
\hline $\begin{array}{l}\text { Accepted: } \\
10.06 .2021\end{array}$ & $\begin{array}{l}\text { Physics Laboratory- } 2 \text { course, each lasted } 1,5 \text { hours long. } 16 \text { female } \\
\text { freshman students participated in the study voluntarily. In the laboratory, }\end{array}$ \\
\hline Key words: & the students performed their experiments in four groups. The laboratory \\
\hline $\begin{array}{l}\text { Practical skills, } \\
\text { Physics laboratory, } \\
\text { Simple electric circuit }\end{array}$ & $\begin{array}{l}\text { environment was recorded with one camera, and each group had one } \\
\text { audio recorder. The video recordings and sound recordings were then }\end{array}$ \\
\hline & $\begin{array}{l}\text { In the first week, necessary experimental materials were explained in } \\
\text { detail and students made serial and parallel circuits with two resistances, } \\
\text { measurements with ammeter and voltmeter. In the second week, students } \\
\text { were required to set up different circuits which can be done with } 3 \\
\text { resistors, and to make current and potential difference measurements in } \\
\text { these circuits. The results of this research were presented with three main } \\
\text { headings. First, the students' processes of establishing simple electrical } \\
\text { circuits were described by emphasizing the differences among the groups. } \\
\text { Later, students' difficulties in the process of establishing simple electrical } \\
\text { circuits were identified. Finally, examples were given on the strategies of } \\
\text { the students to solve the difficulties they were experiencing. It was } \\
\text { concluded that systematic procedural techniques like following circuit } \\
\text { diagrams or repeated comparisons of diagrams with the circuit may } \\
\text { provide productive habits to reduce errors in the process of establishing } \\
\text { simple electric circuits. }\end{array}$ \\
\hline
\end{tabular}

\section{Introduction}

Content knowledge was seen as one of the prominent prerequisites for teaching a topic by scholars (Loughran, Mulhall, \& Berry, 2008; Rollnick, 2017). This idea led to an increase in the weight of field courses in teacher education programs. Nonetheless, there has been little agreement on the nature and profundity of the content knowledge required or how it ought to

\footnotetext{
*Correspondency: cezmi.unal@gop.edu.tr
} 
be gained (Adler et al. 2009). It is generally accepted that a teacher should have more knowledge than s/he will teach but the boundaries of the content knowledge are blurred. Although Kind (2014) demonstrated rich content knowledge would increase teachers' confidence in teaching their subjects and contribute to student learning, Chan and Hume (2019) stated that a rich content knowledge would not be sufficient alone for most of the teaching contexts. The effect of pedagogical knowledge in teaching is undeniably important. The acquisition of pedagogical knowledge is one of the most important elements of the development of preservice teachers' professional development (Depaepe \& König, 2018).

In the mid-1980s, Shulman (1986) proposed a significant idea to the education community namely pedagogical content knowledge. He differentiated subject knowledge learned in academic settings and the knowledge needed to teach that subject in school settings. $\mathrm{He}$ defined pedagogical content knowledge as "the blending of content and pedagogy into an understanding of how particular topics, problems, or issues are organized, represented, and adapted to the diverse interests and abilities of the learner, and presented for instruction" (Shulman, 1987, p. 8). Pedagogical content knowledge takes attention to the compact link between knowledge and practice of teaching that knowledge by revealing the mutual influence. According to Ball, Thames, and Phelps (2008) this idea had two major contributions to the teacher education research. First, it shaped the study of teacher knowledge with the focus directed to the content in teaching. Second, the meaning of content knowledge of teachers transformed to a kind of technical knowledge with the emphasis on professional aspects.

Ball, Thames and Phelps (2008) valued the idea of pedagogical content knowledge and presented a refinement of Shulman's categories. They proposed that content knowledge can be subdivided into common content knowledge and specialized content knowledge, whereas pedagogical content knowledge subdivided into knowledge of content and students, and knowledge of content and teaching. Among these subcategories specialized content knowledge is the subject of this paper because laboratory works in teacher education programs are placed in this subcategory. Specialized content knowledge can be defined in science education as science knowledge required only for science teachers to help their teaching practice without requiring knowledge of students and teaching (Kind, 2009). Specialized content knowledge is closely related to the teaching practice like pedagogical content knowledge; however, it is most viable for general circumstances of science education settings.

Laboratory always has a distinctive and central role in science education. In the beginning, a laboratory was seen as the place where previously learned scientific knowledge was illustrated and confirmed (Hofstein \& Kind, 2012; Wheeler, Maeng, Chiu \& Bell, 2017). With the reform movements all around the world, the form of laboratory instruction turned into investigation, discovery or inquiry (Lunetta, Hofstein \& Clough, 2007). Laboratory work became the core of science education and the importance of science process skills increased. However, comprehensive research of academicians showed conflicting results on the efficacy and benefits of laboratory studies (Hofstein \& Lunetta, 2004; Seery, 2020). For example, Hofstein and Kind (2012) asserted that reviews on the issues of the laboratory had strong difficulties about the educational effectiveness in different domains. Although, there was convincing evidence that laboratory instruction had a positive effect on laboratory manipulative skills, there was little or no evidence for its effects on subject learning, conceptual understanding, and critical thinking (Ferreira \& Morais, 2020). 
The studies about the school laboratory carried out in the last ten years are mostly under the name of practical work with the influence of the UK literature. Practical work can be defined as "activities in which the students manipulate and observe real objects and materials" (Abrahams \& Millar, 2008, p. 1945) in the general sense. Practical work depends on students' active learning by using inquiry or discovery in the context of hands-on and mind-on activities. Theoretically, meaningful science learning and the development of critical thinking skills can be acquired through practical work (Schwichow, Zimmerman, Croker \& Härtig, 2016). However, putting this idea into practice in school laboratories is still not fully achieved. Some researchers reported that practical work is still insufficient in most of the school science laboratories (Abrahams, Reiss \& Sharpe, 2013; Fadzil \& Saat, 2017; Fuccia, Witteck, Markic \& Eilks, 2012). This situation may arise because students need a high cognitive load during practical work (Johnstone \& Wham, 1982). During practical work, students need to deal with a lot of challenging tasks like encountering first time experimental materials they do not know how to use or dealing with experimental errors. These kinds of challenging demands may be discouraging for students as well as teachers.

The paucity of practical work in science education may be resulted in students' having to deal with the problem of acquiring specific skills in manipulating scientific devices and equipment in the laboratory. The academic works strongly asserted that students have difficulties using and manipulating laboratory equipment skilfully (Fadzil \& Saat, 2017; Grant, 2011; Tesfamariam, Lykknes \& Kvittingen, 2015). One of the important goals of practical work is the development of manipulative skills. Mutually, continuous exposure to practical work by experimenting within different subject areas is one of the best ways to develop manipulative skills (Abrahams, Reiss \& Sharpe, 2013). The inability of students to acquire manipulative skills can seriously affect the acquisition of other desired laboratory skills like data recording and reporting. Moreover, students who are proficient in manipulative skills would have better opportunities to focus on the development of science process skills in inquiry type practical work (Darmaji, Kurniawan \& Irdianti, 2019; Johnstone \& Al-Shuaili, 2001). Therefore, it is necessary to increase the practical work experiences of preservice science teachers in order to provide them with manipulative skills and increase the potential of using them in their future classes.

Like all the topics of science education, studies in the simple electric circuit, whether with or without practical work, were extensively focused on conceptual understanding of the topic (Duit, Schecker, Höttecke, \& Niedderer, 2014; Husnaini \& Chen, 2019; McDermott \& Shaffer, 1992; Moodley \& Gaigher, 2019; Peşman \& Eryılmaz, 2010). These studies tried to reveal how simple electrical circuits are learned and structured in the mind. For example, Rieger et. al. (2016) emphasized the essential role of the usage of Tutorials of Introductory Physics (Shaffer \& McDermott, 1992) like laboratory based instructions on the tertiary level to help students overcome conceptual difficulties. On the other hand, Malik, Setiawan, Suhandi, and Permanasar (2017) implemented an electric circuit version of Higher Order Thinking Laboratory (HOT Lab) to the pre-service physics teachers and found that in this kind of laboratory activities students have the opportunities of enhancing creative thinking skills as well as science process skills. However, a part of the practical skills of the picture is still mostly missing. Practical skills are generally given the least attention by the researchers despite its importance (Fadzıl \& Saat, 2017). This study tried to compensate this shortcoming by investigating prospective science teachers' process of constructing simple electric circuits. 


\section{Method}

\section{Research Design}

In this study, embedded single case study design, which is one of the qualitative research designs, was used. The embedded single case study design is described as a case study that contains more than one unit of analysis (Y1ldırım \& Şimşek, 2016; Yin, 2003). In this study pre-service science teachers' processes of making simple electrical circuits were taken as a case and each groups' conducting one experiment with a simple electrical circuit constituted a unit of analysis. It was tried to describe the features, context, and process of preservice science teachers' processes of making simple electrical circuits by defining and comparing each groups' experimentation process.

\section{Study Group}

This study took place at the Physics Laboratory-2 course of Tokat Gaziosmanapaşa University of Turkey, Faculty of Education, Department of Science Education during the Spring Semester of 2016-2017 Academic Year. Participants of the study were chosen according to convenient sampling method (Yıldırım \& Şimşek, 2016). Convenient sampling was preferred in order to provide accessibility and practicality to the research. Among the total of 57 freshman students of the department (52 female and 5 male), 16 students participated in the study voluntarily. All the participants were female and had an average 72,38 GPA in the previous semester. Since only these 16 female students were volunteers in the study where there were already many female students, all participants were female. In the laboratory, students performed their experiments in four groups each containing four students. In order to ensure confidentiality, numbers were used in this article instead of student names.

\section{Data Collection Process}

All of the theoretical content about simple electric circuit was covered before the laboratory sessions in an introductory physics course. The lesson related to simple electric circuit took two hours. First hour contained basic laws and calculations of simple electric circuit using Ohm Law. The second hour included calculations of different serial and parallel circuits.

The subject of the study was the two weeks of the laboratory course in which students did experiments about simple electrical circuits. Each laboratory session lasts 1, 5 hours long approximately. In the first week, necessary experimental equipment was explained in detail and students made serial and parallel circuits with two resistances, they also did measurements with ammeter and voltmeter. In the second week, students were required to set up different circuits which can be done with 3 resistors, and to make current and potential difference measurements in these circuits. There were a total of 4 circuit diagrams at laboratory worksheets in the second week. These circuits were three resistors serial to each other, three resistors parallel to each other, two resistors serial to each other and the third one parallel to them, and two resistors parallel to each other and third one serial to them.

The laboratory environment in which the experiments were carried out is in the form of a standard high school physics laboratory, which is on the catalogue of the Turkish State Office of Materials. All the necessary experimental equipment was in the laboratory cabinets, except those mounted on the tables. Students needed to determine and then take the equipment from the cabinets for experiments. Students used the rheostat, resistance series, power supply, 
connection cables, an ammeter and voltmeter, which can be found in the catalogue of the DAYM (Turkish Educational Tools Manufacturing Centre), while setting up the simple electrical circuits.

\section{Data Collection Tools and Analysis}

The data sources of the study were included observations of the participants while they were establishing simple electric circuits and making measurements with an ammeter and voltmeter, and laboratory worksheets filled by each group. The laboratory environment was recorded with one camera, and each group had one audio recorder. These recordings began with participants' entrance to the laboratory in each laboratory session and finished at the end of the session. There were a total 2 video records and 8 audio records. Video recordings were used for capturing participants' behaviors, while audio records were used for capturing conversations among group participants during simple electric circuit process. Laboratory worksheets were another data source for this study. Each group filled one laboratory worksheet for each laboratory session. There were a total 8 filled laboratory worksheets. These laboratory worksheets were evaluated as the correctness of the measurement results.

The analysis of the raw data was conducted basis on the unit of analysis. All data about each groups' conducting one experiment with simple electrical circuit were handled together. The video recordings and sound recordings were synchronized and evaluated together with related laboratory worksheets. Descriptive analysis was chosen for the description of processes. In the descriptive analysis, the obtained data is summarized and interpreted according to previously determined themes (Yıldırm \& Şimşek, 2016). The themes were the processes of establishing simple electric circuits, problems experienced in these processes, and strategies to solve these problems.

\section{Trustworthiness of the Study}

In this study, trustworthiness of the study was tried to be fulfilled according to the criteria proposed by Lincoln and Guba (1985). One of them was prolonged engagement. Because the researcher was experienced in laboratory sessions and worked in his laboratory, he could understand the research site fully to avoid the distortions of data. Moreover, a comfortable laboratory environment was provided for participants to focus on their circuits and speak freely. Persistent observation was applied by repeated reviews of sound and video recordings. Triangulation was tried to be implemented by multiple sources of evidence to increase trustworthiness of study. The findings of this study employed different kinds of data sources like laboratory worksheets, video recordings and sound recordings. In this study, all the processes about research, data and data analysis were explained in detail to show the consistency of findings and interpretations. In this manner dependability and confirmability of the study were attempted to be established.

\section{Results}

In this section, pre-service science teachers' processes of making simple electrical circuits in the context of the Physics Laboratory II course were presented with three main headings. First, the students' processes of making simple electrical circuits were described by emphasizing the differences among the groups. Later, students' difficulties in the process of making a simple electrical circuit have been identified. In addition, sources of the difficulties 
were tried to be pointed out in order to reach possible solutions. Finally, examples were given on the strategies of the students to solve the difficulties they were experiencing.

\section{Processes of Establishing a Simple Electric Circuit}

All of the groups firstly looked through the schematic circuit diagram given to them and tried to determine whether the circuit elements are serial or parallel to each other. After the group members reached a consensus among themselves, they started to build the circuit by bringing the necessary equipment from the laboratory cabinets to their desks. When the processes of making simple electrical circuits of the groups were examined, it was observed that two different strategies were followed. The first one was, seen in three groups, unplanned connections of circuit elements. One group used the strategy of following the schematic circuit diagram starting from the main branch. After all groups had built their circuits, they confirmed the correctness of the circuit according to the approval of the course supervisor and the appearing value of the measuring instruments when the power source opened.

\section{Unplanned Connections of Circuit Elements}

The most common strategy for the groups during the building process of a simple electric circuit is the strategy of unplanned connections of circuit elements. The common characteristics of the circuit building work using this strategy were as follows. They started building a circuit with any circuit elements they chose. Mostly, they began with resistors. If there was more than one resistor, they paid attention to whether resistors were series or parallel to each other. Then they tried to add other circuit elements. They did not pay attention to the sequence of the circuit elements in the circuit diagram. The general characteristic of this strategy was that the pre-service teachers focused on only one part of the circuit and did not think about the whole circuit. The most frequent speech in the group when building a circuit with this strategy was "Where should we connect this?" while they were holding one end of the connecting lead and the other end was plugged into any circuit element. After setting up the connections, it was observed that they frequently checked the circuit mentally. When the groups were making their circuit, they did not know exactly what they were doing and tried to conclude by trial and error without thinking about it.

\section{Following Circuit Diagram}

The less observed strategy while pre-service teachers were making simple electric circuits was following the circuit diagram. Students who used this strategy usually start the circuit from the power source. Then they tried to connect the other circuit elements by taking into account the order in the circuit diagram. In the circuit making process, they frequently checked the circuit they built by comparing it with the schematic circuit diagram. The most frequent speech in the groups when building a circuit with this strategy was "What is next?" by pointing out their group friend to look at the schematic circuit diagram. The general characteristics of this strategy were identifying the circuit elements with the symbols in the schematic circuit diagram, focused on the whole circuit, and continuous circuit diagram check.

\section{Difficulties in the Process of Making a Simple Electrical Circuit}

It was observed that the groups encountered many difficulties in the process of making a simple electrical circuit. The identified problems were presented in this section. In addition, 
in order to understand the source of these problems, discussions in the laboratory process were examined in detail.

\section{Connect Only One Output of the Circuit Elements to the Circuit}

As is known, each circuit element has two outputs and in order to establish a closed circuit, it is necessary to connect both outputs to the circuit correctly. In the beginning of the first lesson, although a detailed description of the circuits and using circuit elements were given to the whole class, it was seen that some of the circuit elements connected with only one output to the circuit or a cable connected to the circuit element is idle, especially at the first attempts. In addition, it was determined that these kinds of situations were progressively decreasing throughout the sessions. In most cases, it was understood that they were not aware of the situation when they were asked why they made the circuit in this way. On one occasion there was an interesting answer appeared. One participant answered the question as "Why not? Television is also connecting with a single cable." It seemed that participant resembled television with the simple electric circuit and gave a rationale for their connections with these resembled situations. The participant was informed that there are two different wires inside the cable as it seems to be connected with a single cable. They should connect two outputs of every circuit element properly.

\section{Connecting the Two Outputs of a Circuit Elements to the Same Point when Connecting in Parallel}

When the circuit elements are to be connected in parallel, one output of the circuit elements is connected to the other and the remaining outputs of the circuit elements are connected to each other. If the two outputs of a circuit element are connected to the same point, it is short-circuited and this circuit element does not have an effect on the circuit. When the groups tried to establish a parallel connection, it was observed that for many times a circuit element was connected both ends to the same point and created a short-circuit. This situation was more common when there were three resistors in the circuits to be installed. When the participants were asked whether there was a short-circuit in their circuit, they were not able to detect it. They were easily convinced or seemed to be convinced when the connections that created short-circuit were shown. Although they possessed the procedural understanding of a short-circuit, they could not locate it in their established circuit even if they tried to find out it.

\section{Misunderstanding the Schematic Circuit Diagram}

Schematic circuit diagrams show the circuit elements are whether serial or parallel to each other. Students need to read the schematic circuit diagram correctly and understand it to establish a proper circuit. When they misunderstand the schematic circuit diagram, there is no way to make the right circuit. Especially, the circuit has a parallel connection of circuit elements, student sometimes had some understanding difficulties about which elements are series and which elements are parallel connections to each other. For example, when students were asked to make the circuit described with a diagram in the Figure 1, the following conversation happened in Group 4. 


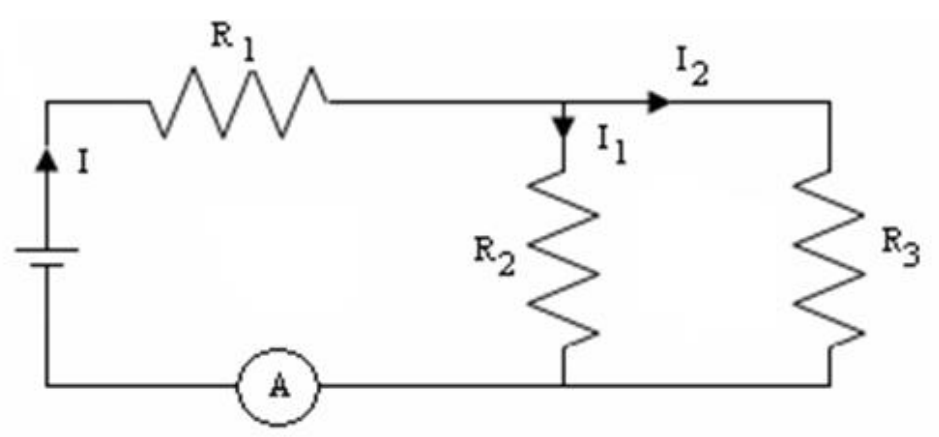

Figure 1. Schematic circuit diagram for two resistors serial to each other and the third one parallel to them

S41: Which resistors are parallel to each other?

S42: I think R1 and R2.

S43: No no. Power supply, R2, and $R 3$ are parallel and $R 1$ serial to all of them.

S41: Power supply and RI are serial ...they are following each other.

S42: Then power supply, RI and R2 following each other. $R 3$ parallel to all of them. (Conversation went on like this and the group did not reach a consensus. They asked for help from another group.)

\section{Connecting Three Terminals of the Slide Rheostat to the Circuit}

Slide rheostats are often used for education in school laboratories which can be employed as a variable resistor or fixed resistor. There are three terminals on the rheostat for this multifunction. On the other hand, it must be connected with two of the terminals in a circuit according to the intended use. Before the laboratory session, all this information was given to the students and explained in detail. When students used the rheostat as a resistor, it was observed that some groups connect all the three terminals of the rheostat to the circuit. This situation occurred more frequently when there are parallel connections in the circuit. Picture 1 presents the picture of Group 1's established circuit of two resistors parallel to each other and the third one serial to them (circuit in Figure 1).

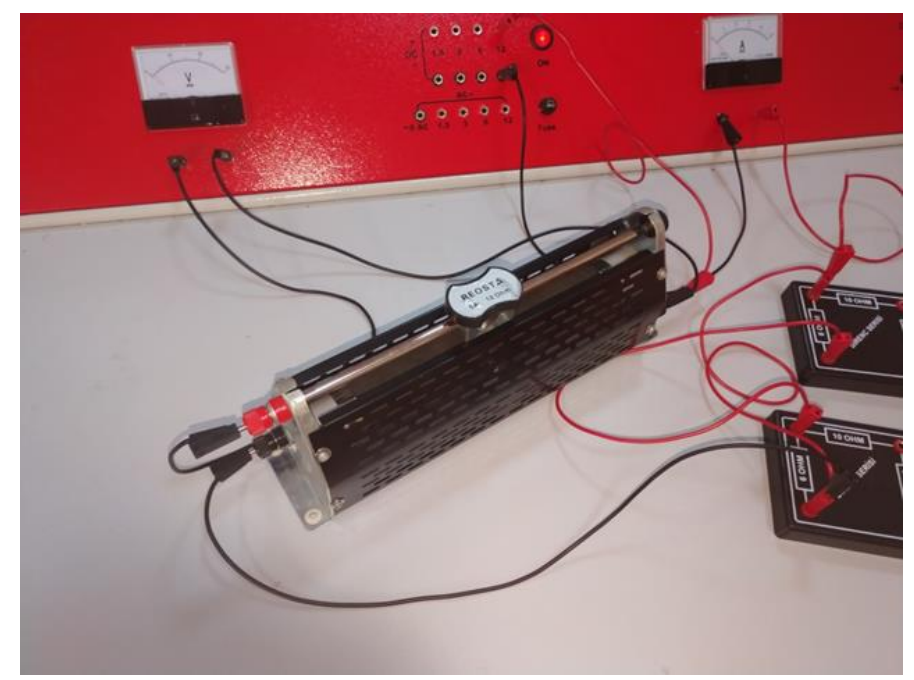

Pictıure 1. Group 1 established a circuit for two resistors serial to each other and the third one parallel to them 


\section{Incorrectly Connecting Measuring Instruments}

One of the aims of the electric laboratory practice is to learn how to use measuring instruments properly. In accordance with this purpose, the students were asked to measure the potential difference between the ends of each circuit element and the current passing through them. For example, after students set up the circuit in Figure 1, they tried to measure potential differences across the power supply, R1, R2 and R3 and the current pass through on the main branch and parallel branches. In this process, they had to break down and rebuild some parts of the circuit over and over again. While Group 3 was measuring I1 current, the following conversations took place within the group members:

S31: Let's measure the I1 current. What do we need to do?

S32: Connect the ammeter to the R2. (Because they measured I current previously, it was on the main branch.)

S31: Which one R2? (Group members looked approximately 30 seconds to the circuit to decide R2. After they decided R2, S32 connected ends of ammeter to the ends of R2 with connecting leads)

S33: What are you doing? First, we have to disconnect it.

S32: Ok. (S32 unplugged previously connected cables and did not plug it anywhere)... Is it ok?

S31: Ok. Let's check it. (Group turned on the power source and the ammeter did not show a value.)

Because the voltmeter is connected parallel to the circuit element and the ammeter is connected serially to the branch when measuring, students experienced many difficulties, especially at the first attempts. Students did not notice sometimes open cables, sometimes if the connection was serial or parallel, or sometimes the exact placement of the ammeter. They needed to check all the circuit for troubleshooting when problems appeared. It was seen that these difficulties gradually decreased as the laboratory experiences with circuits and the measuring instruments increased.

\section{Strategies to Solve Difficulties}

As stated in the previous section, students encountered many problems while they were trying to set up a simple electric circuit. Because of these difficulties, their circuits did not work or the instructor asserted that there was a fault in the circuit. Opportunities to solve these difficulties in the group were given within a certain period of time. It was observed that two strategies were generally used while solving the difficulties. One of them was the haphazard replacement of connections or equipment. The other one was the comparison of established circuit with the schematic circuit diagram. These strategies are explained in detail in the following headings.

\section{Haphazard Replacement of Connections or Equipment}

Haphazard replacement of connections or equipment was the most common used strategy for students when they encountered an inoperative circuit. Especially groups who used unplanned connection of circuit elements strategy during the establishment process showed this kind of behaviour. For example, after Group 2 established the 3 resistors in a parallel circuit, they realized that measuring instruments did not show a value. The following conversations took place within the group members: 
S21: It didn't work.

S22: What is the problem?

S21: I don't know. Probably connections. We used too many connecting wires

in this circuit.

S22: Yes. Let's try changing this. (She unplugged the connecting wire and put it on the other edge of the resistor.)

S22: Turn on it.

The conversation in group showed that they think the error source is connections. In such a case, they would be expected to compare the connections with the schematic circuit diagram for troubleshooting. However, observations showed that they preferred to randomly change connections without comparison. This behaviour sometimes gave results but mostly did not work well, to cap of all off, it could mess the circuit up more.

\section{Comparison of Established Circuit with the Schematic Circuit Diagram}

It is a common strategy to compare the established circuit with the schematic circuit diagram during the circuit establishment process in school laboratories. Efforts are made to gain this habit in laboratory studies most of the time. In this study, being not any different, the students were encouraged to compare the schematic circuit diagram with the circuit they built continuously. This happened not only during the building process but also during the troubleshooting process. The frequency of students' using this strategy in their lab sessions gradually increased. However, it did not work well in all the try outs. For example, while Group 4 established the three resistors in a parallel circuit, it did not work. They could not find the problem although they checked all the connections and made the necessary comparison of the circuit diagram and established circuit. When their patience was about to exhaust, a brilliant idea came from one of the group members. He proposed to draw an established circuit's schematic circuit diagram and compare it with the given schematic circuit diagram. The group implemented this idea and found the source of error. The circuit worked well with the help of a modified version of the comparison strategy.

\section{Discussion}

The focus of this study was gaining insights into the procedural understanding and the practical skills of pre-service science teachers in the context of establishing simple electric circuits. In order to achieve this, simple electric circuit processes with different connections were observed in detail because observation is the best way of assessing the practical skills (Abraham \& Reiss, 2015). Pre-service science teachers experienced many difficulties in the establishment process of the simple electric circuit, especially with three resistors, and using ammeter and voltmeter properly. Like the Gülçiçek and Kanlı (2018) found about university students, participants did not know how to use some laboratory equipment exactly. For example, for many of them, it was the first time they used rheostat as a resistor in a circuit. In many cases, they performed unplanned connections of circuit elements and they had different difficulties during the establishment and measurement process. The time spent on the constructing simple electric circuit prevented them from considering the results obtained more carefully. However, acquiring these kinds of skills is one of the aims of electric laboratory instruction (Urbano, 2018). The difficulties gradually decreased as the students spent time in the laboratory and established different circuits.

Experience with lab equipment is one of the most valuable factors for students to be able to successfully carry out experiments (Ferreira \& Morais, 2020). In order to acquire practical 
skills, students need to do different experiments with related lab equipment. Systematic procedural techniques like following circuit diagrams or repeated comparisons of diagrams with the circuit may provide productive habits to reduce errors in the process of establishing simple electric circuits. These kinds of good techniques may reduce the misinterpretations by minimizing the error sources in lab experiments (Preston, 2019). The results of this study showed that participants' practical skills on making simple electric circuits were very basic. Although they possessed procedural understanding of making a simple electric circuit, they had many difficulties during the lab sessions. This result is parallel to Fadzil \& Saat (2017), whose study revealed that there is a gap between theoretical knowledge of handling lab equipment and actual performance of executing experiments.

Grant (2011) has shown that lack of experience in laboratory settings in the previous schools is the most contributing factor to the lack of practical skills at the university level. She also emphasized that lack of practical skills influence the confidence levels in performing experiments negatively. This is in line with the results of the Buffler, Allie and Lubben (2001) which reported that improving practical skills depends on repeated experiences in different laboratory works. It seems that there is consensus in the literature that students need to do systematic laboratory experimentation in different subject areas to get mastery on practical skills. However, there are different ideas about the pathway of the acquisition of practical skills efficiently.

Fadz1l and Saat (2017) proposed a hierarchical pattern to acquire students' advanced practical skills. This hierarchical pattern can be used in laboratory sessions to increase students' ability to operate the experiment efficiently. On the other hand, Finkelstein et al. (2005) proposed doing experiments by using computer simulations before the real laboratory. Their study showed that doing simulations about simple electric circuit before the experiments with real equipment provide more productive results on conceptual understanding and manipulating real materials. These kinds of adjustments in laboratory classes may be beneficial for students acquiring practical skills.

\section{Note}

This study was presented at the International Learning Teaching and Educational Research Congress (ILTER-2018) as an oral presentation.

\section{References}

Abrahams, I., \& Millar, R. (2008). Does practical work really work? A study of the effectiveness of practical work as a teaching and learning method in school science. International Journal of Science Education, 30(14), 1945-1969.

Abrahams, I., Reiss, M. J., \& Sharpe, R. M. (2013). The assessment of practical work in school science. Studies in Science Education, 49(2), 209-251.

Abrahams, I., \& Reiss M. J.. (2015). The assessment of practical skills. School Science Review, 96 (357), 40-44.

Adler, J., Pournara, C., Taylor, D., Thorne, B., \& Moletsane, G. (2009). Mathematics and science teacher education in South Africa: A review of research, policy and practice in times of change. African Journal of Research in Mathematics, Science and Technology Education, 13, 28-46.

Ball, D. L., Thames, M. H., \& Phelps, G. (2008). Content knowledge for teaching: What makes it special? Journal of Teacher Education, 59, 389-407. 
Buffler, A., Allie, S., \& Lubben, F. (2001). The development of first year physics students' ideas about measurement in terms of point and set paradigms. International Journal of Science Education, 23(11), 1137-1155.

Chan, K. K. H., \& Hume, A. (2019). Towards a consensus model: Literature review of how science teachers' pedagogical content knowledge is investigated. In A. Hume, R. Cooper \& A. Borowski (Eds.), Repositioning PCK in teachers' professional knowledge for teaching science (3-76). Singapore: Springer.

Darmaji, D., Kurniawan, D. A., \& Irdianti, I. (2019). Physics education students' science process skills. International Journal of Evaluation and Research in Education, 8(2), 293-298.

Depaepe, F., \& König, J. (2018). General pedagogical knowledge, self-efficacy and instructional practice: Disentangling their relationship in pre-service teacher education. Teaching and Teacher Education, 69, 177-190.

Duit, R., Schecker, H., Höttecke, D., \& Niedderer, H. (2014). Teaching physics. In N. G. Lederman \& S. K. Abell (Eds.), Handbook of research in science education (Vol. 2, 434-456). New York, NY: Routledge.

Fadzil, H. M., \& Saat, R. M. (2017). Exploring students' acquisition of manipulative skills during science practical work. Eurasia Journal of Mathematics, Science and Technology Education, 13(8), 4591-4607.

Ferreira, S., \& Morais, A. M. (2020). Practical work in science education: Study of different contexts of pedagogic practice. Research in Science Education, 50, 1547-1574.

Finkelstein, N. D., Adams, W. K., Keller, C. J., Kohl, P. B., Perkins, K. K., Podolefsky, N. S., Reid, S., \& LeMaster, R. (2005). When learning about the real world is better done virtually: A study of substituting computer simulations for laboratory equipment. Physical Review Special Topics-Physics Education Research, 1(10103), 1-8.

Fuccia, D., Witteck, T., Markic, S., \& Eilks, I. (2012). Trend in practical work in German science education. Eurasia Journal of Mathematics, Science and Technology Education, 8(1), 59-72.

Grant, L. (2011). Lab skills of new undergraduates: Report on the findings of a small scale study exploring university staff perceptions of the lab skills of new undergraduates at Russell Group Universities in England. London, United Kingdom: Gatsby Charitable Foundation.

Gülçiçek Ç. \& Kanlı U. (2018), Pre-service physics teachers' recognition of apparatuses used in mechanics and electricity and magnetism experiments. Universal Journal of Educational Research 6(12), 2864-2874.

Hofstein, A., \& Lunetta, V. N. (2004). The laboratory in science education: Foundations for the twenty-first century. Science Education, 88(1), 28- 54.

Hofstein, A., \& Kind, P. M. (2012). Learning in and from science laboratories. In B. J. Fraser, K. G. Tobin, \& C. J. McRobbie (Eds.), Second international handbook of science education (189-207). Dordrecht: Springer.

Husnaini, S. J., \& Chen, S. (2019). Effects of guided inquiry virtual and physical laboratories on conceptual understanding, inquiry performance, scientific inquiry self-efficacy, and enjoyment. Physical Review Physics Education Research, 15(1), 1-16.

Johnstone, A. H., \& Al-Shuaili, A. (2001). Learning in the laboratory: Some thoughts from the literature. University Chemistry Education, 5, 42-51.

Johnstone, A. H., \& Wham, A. J. B. (1982). The demands of practical work. Education in Chemistry, 19, 71-73.

Kind, V. (2009). Pedagogical content knowledge in science education: Perspectives and potential for progress. Studies in Science Education, 45(2), 169 - 204. 
Kind, V. (2014). Science teachers' content knowledge. In H. Venkat, M. Rollnick, M. Askew, \& J. Loughran (Eds.), Exploring mathematics and science teachers' knowledge: Windows into teacher thinking (15-28). Oxford: Routledge.

Lincoln, Y. S., \& Guba, E. G. (1985). Naturalistic inquiry. Beverly Hills. CA:Sage.

Loughran, J., Mulhall, P., \& Berry, A. (2008). Exploring pedagogical content knowledge in science teacher education. International Journal of Science Education, 30(10), 1301 1320

Lunetta, V. N., Hofstein, A., \& Clough, M. P. (2007). Learning and teaching school science laboratory: An analysis of research, theory, and practice. In S. K. Abell \& N. G. Lederman (Eds.), Handbook of research on science education (393-441). Mahwah, NJ: Lawrence Erlbaum.

Malik, A., Setiawan, A., Suhandi, A., \& Permanasar, A. (2017). Enhancing pre-service physics teachers' creative thinking skills through hot lab design. AIP Conference Proceedings, 1868 (070001), 1-7.

McDermott, L. C., \& Shaffer, P. S. (1992). Research as a guide for curriculum development: An example from introductory electricity. Part 1: Investigation of student understanding. American Journal of Physics, 60(11), 994-1013.

Moodley, K., \& Gaigher, E. (2019). Teaching electric circuits: Teachers' perceptions and learners' misconceptions. Research in Science Education, 49, 73-89.

Osborne, J. (2015). Practical work in science: Misunderstood and badly used? School Science Review, 96(357), 16-24.

Peşman, H., \& Eryılmaz, A. (2010). Development of a three-tier test to assess misconceptions about simple electric circuits. The Journal of Educational Research, 103(3), 208-222.

Preston, C. M. (2019). Effect of a diagram on primary students' understanding about electric circuits. Research in Science Education, 49, 1433-1456.

Riegler, P., Simon, A., Prochaska, M., Kautz, C., Bierwirth, R., Hagendorf, S., \& Kortemeyer, G. (2016). Using Tutorials in Introductory Physics on circuits in a German university course: Observations and experiences. Physics Education, 51(6), 115.

Rollnick, M. (2017). Learning about semiconductors for teaching-the role played by content knowledge in Pedagogical Content Knowledge (PCK) development. Research in Science Education, 47, 1-36.

Schwichow, M., Zimmerman, C., Croker, S., \& Härtig, H. (2016). What students learn from hands-on activities? Journal of Research in Science Teaching. 53(7), 980-1002.

Seery, M. K. (2020). Establishing the laboratory as the place to learn how to do chemistry. Journal of Chemical Education. 97, 1511-1514.

Shaffer, P. S. \& McDermott, L. (1992). Research as a guide for curriculum development: an example from introductory electricity, Part II: Design of instructional strategies. American Journal of Physics, 60 (11), 1003-1013.

Shulman, L. S. (1986). Those who understand: Knowledge growth in teaching. Educational Researcher, 15(2), 4-14.

Shulman, L. S. (1987). Knowledge and teaching: Foundations of the new reform. Harvard Educational Review, 57, 1-22.

Tesfamariam, G. M., Lykknes, A., \& Kvittingen, L. (2015). Named small but doing great: An investigation of small-scale chemistry experimentation for effective undergraduate practical work. International Journal of Science and Mathematics Education, 13(1), 118.

Urbano, D. (2018). Effectiveness of traditional laboratory classes to learn basic concepts of electric circuits: A case study. In Auer M., Guralnick D., \& Simonics I. (Eds), Teaching and learning in a digital world (693-701), Springer. 
Wheeler, L. B., Maeng, J. L., Chiu, J. L., \& Bell, R. L. (2017). Do teaching assistants matter? Investigating relationships between teaching assistants and student outcomes in undergraduate science laboratory classes. Journal of Research in Science Teaching, 54(4), 463-492

Yıldırım, A. \& Şimşek, H. (2016). Sosyal bilimlerde nitel araştırma yöntemleri (10. baskl) [Qualitative research methods in social sciences. (10th ed.)]. Ankara: Seçkin Publ.

Yin, R. K. (2003). Case study research, design and methods, 3rd ed. Newbury Park: Sage Publications. 